\title{
Alteration indices at high resolution, from hyperspectral scanning of drill holes in western Tasmania, Australia
}

\author{
D.C. GREEN $^{1 *}$
}

${ }^{1}$ Mineral Resources Tasmania, 30 Gordons Hill Road, Rosny Park, Tasmania 7018, Australia (*correspondence:

david.green@stategrowth.tas.gov.au)

Hydrothermal alteration haloes surround volcanic massive sulphide (VMS) deposits, and provide an important targeting framework for mineral exploration. The intensity of alteration is quantified by alteration indices calculated from lithogeochemistry. These are interpreted in terms of mineral replacement trends to give estimates of proximity to ore. Spatial resolution is typically limited to sparse meter-scale samples and the analytical method is slow.

Automated hyperspectral scanning of drill core offers increased resolution and rapid data acquisition, but provides mineralogy rather than chemistry. Nevertheless, estimates of Ishikawa Alteration Index (AI) and the chlorite-carbonatepyrite index (CCPI) can be calculated from mineral proportions and composition.

In this study, HyLogger spectra from drill holes intersecting VMS alteration in the Mt Read Volcanics of western Tasmania provides mineralogy then used to estimate alteration indices. The indices generally correlate with those derived lithogeochemically, but significant discord is apparent, especially for CCPI, in zones where the mineralogy is insufficiently characterised.

When the hyperspectral data is plotted on an Alteration Box Plot (AI vs CCPI), domains characterised by specific mineral replacement (e.g. sericite) become apparent. In addition, the high spatial resolution of hyperspectral data enables the significance of localised alteration to be assessed and for late stage veins not associated with alteration to be masked out.

This project demonstrates that hyperspectral scanning supports and augments the identification and interpretation of alteration trends using standard geochemical mineral exploration methods.

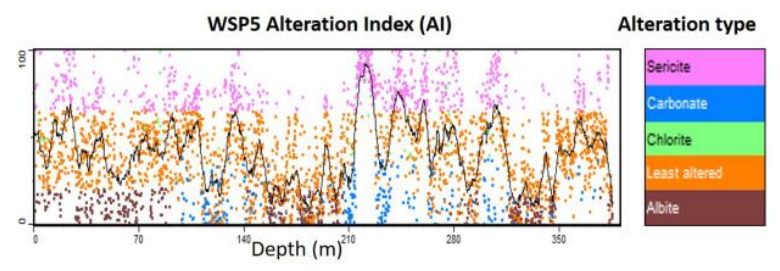

